\title{
Down-Regulation of Rho GTPase-Activating Protein 7 (DLC1) in Tear Film and Modulation of Rho GTPase Dynamics by Rosuvastatin in Dogs Suffering from Keratoconjunctivitis Sicca
}

\author{
Swapana, C.R. ${ }^{1}$, Aswathy Gopinathan ${ }^{1}{ }^{*}$, Kiranjeet Singh ${ }^{1}$, Sasikala, $\mathbf{R}^{1}$., Akshay Kumar ${ }^{1}$, \\ Sowbharenya Chelladuraai ${ }^{1}$, Naveen Kumar ${ }^{1}$, Monalisa Sahoo ${ }^{2}$ and Ravi Kant Agrawal ${ }^{3}$ \\ ${ }^{1}$ Division of Surgery, ICAR-IVRI, Izatnagar, Bareilly (U.P.) Uttar Pradesh, INDIA \\ ${ }^{2}$ Division of Pathology, ICAR-IVRI, Izatnagar, Bareilly (U.P.) Uttar Pradesh, INDIA \\ ${ }^{3}$ Division of LPT, ICAR-IVRI, Izatnagar, Bareilly (U.P.) Uttar Pradesh, INDIA \\ *Corresponding author: A Gopinathan; E-mail: aswathykiran77@gmail.com
}

Received: 26 Sept., 2020

Revised: 13 Oct., 2020

Accepted: 13 Nov., 2020

\begin{abstract}
Rho GTPases activity in tear fluid as well as ocular surface epithelium (OSEC) during progression of Keratoconjunctivitis sicca (KCS) and their modulation with Rosuvastatin in dogs was studied. Based on Schirmer's tear test, KCS cases were staged as early $(n=21)$ and late KCS $(\mathrm{N}=14)$. Tear and ocular surface epithelial cell samples were collected from all cases for protein and gene expression studies. Rho GTPase activity in different stages of KCS was evaluated by tear fluid 1D-SDS-PAGE, MALDITOF/MS, western blotting and corneal tissue immuno-histochemistry (IHC). Protein expression studies showed increased expression of Rho GTPases in early and late KCS. Effect of Rosuvastatin on progression of KCS was evaluated on 12 client owned dogs divided into two groups A (control group) and B (treatment group) having six dogs in each. Group A dogs were treated with topical eye drops alone whereas, group B animals were treated with topical eye drops and Rosuvastatin orally (a) $0.2 \mathrm{mg} / \mathrm{kg} \mathrm{B.W.} 14$ days. Tear proteomic study revealed significant down-regulation of Rho GTPase-activating protein 7 (DLC1) and up-regulation Rho modulators and Ras-related Rab proteins in KCS cases. Group B dogs showed better response in terms of corneal clarity both clinically and photographically compared to group A. Expression of Rho GTPase proteins was increased in group B compared A post treatment. On Real-Time PCR assay, mRNA expression of RhoA and GDI2 was contained post Rosuvastatin treatment in OSCEs. Rosuvastatin treatment reduced the gene expression of Rho GTPases and blocked the progression of KCS in dogs.
\end{abstract}

\section{HIGHLIGHTS}

(0 Rho GTPases activity in tear fluid as well as ocular surface epithelium (OSEC) during progression of Keratoconjunctivitis sicca (KCS) in dogs was studied.

(0 Rosuvastatin treatment reduced the gene expression of Rho GTPases and blocked the progression of KCS in dogs.

Keywords: DLC1, Rho GTPase, Rosuvastatin, Keratoconjunctivitis sicca, Dog

Canine dry eye disease (Keratoconjunctivitis sicca, $\mathrm{KCS}$ ) has been considered an autoimmune disease owing to its clinical response to immuno-modulatory drugs (Dodi, 2015). Cell polarity clues can be critical for the morphogenesis and function of lacrimal glands and aberrations might lead to immune cell activation. RhoA has a key role in keratinocyte mobilisation, reorganization of actin cytoskeleton, migration and differentiation (Chen et al., 2009). Rho GTPases have prominent role in eukaryotic cell biology. Rho GTPases are key signalling molecules in

How to cite this article: Swapana, C.R., Gopinathan, A., Singh, K. Sasikala, R., Kumar, A., Chelladuraai, S., Kumar, N., Sahoo, M. and Agrawal, R.K. (2020). Down-regulation of rho GTPase-activating protein 7 (DLC1) in tear film and modulation of rho GTPase dynamics by Rosuvastatin in dogs suffering from keratoconjunctivitis sicca. J. Anim. Res., 10(6): 889-898.

Source of Support: None; Conflict of Interest: None 
T lymphocyte development, activation, differentiation and migration, play role in $\mathrm{T}$ cell signalling through antigen receptors, chemokine receptors and integrins (Saoudi et al., 2014). Statins are widely used in the treatment of dyslipidaemia, in addition to providing primary and secondary prevention against cardiovascular disease and stroke. Statins' primary mechanism of action is through the competitive, reversible inhibition of HMG-CoA reductase, the rate-limiting step in cholesterol biosynthesis (McFarland et al., 2014). They can also inhibit prenylation of Ras and Rho proteins, which is important for Rho's interaction with upstream regulators and downstream effectors. Hence by inhibiting Rho prenylation, statins are generally assumed to block Rho activation (Turner et al., 2008).

Studies evaluating the dynamics of classical Rho GTPases RhoA, Rac1 and their regulator GDI2 have not been reported so far in naturally occurring canine KCS. This study assumed cell polarity and cyto-structural aberrations orchestrated by Rho GTPases as key inducers of immune cell migration and might mediate keratinocyte migration and pathological changes in ocular surface epithelial cells. As per authors knowledge present study explored for the first time dynamics of Rho GTPase activity in tear fluid as well as ocular surface epithelium (OSEC) during progression of Keratoconjunctivitis sicca (KCS) and modulation with Rosuvastatin in dogs.

\section{MATERIALS AND METHODS}

\section{Animals}

The study was conducted on client owned dogs presented to Referral Veterinary Polyclinic cum TVCC, IVRI, Izatnagar, Bareilly, Uttar Pradesh with clinical signs of Keratoconjunctivitis sicca. Disease was diagnosed clinically by detailed ophthalmic examination and Schirmer tear testing (STT), confirmation of corneal integrity using fluorescein staining and rose Bengal staining of cornea. Disease onset was assigned as early stage when STT reading was $\leq 15 \mathrm{~mm} / \mathrm{min}$ and disease progression was assigned as late stage when STT reading was $\leq 5 \mathrm{~mm} / \mathrm{min}$. Tear samples from healthy dogs with STT reading $\geq 20 \mathrm{~mm} / \mathrm{min}$ were collected as control. General physical examination and complete blood count (CBC) was carried out to rule out systemic diseases. For
Rosuvastatin treatment, 12 dogs suffering from early or late stages of KCS were selected. They were grouped A and B. Group A dogs suffering from KCS were given topical eye drop Gentamicin and ointment Tacrolimus to be applied two times a day. Group B dogs were given Rosuvastatin (a) $0.2 \mathrm{mg} / \mathrm{kg}$ bodyweight daily for 2 weeks in addition to topical medication. Post treatment observations were recorded weekly for a month (Table 1).

Table 1: Effect of Rosuvastatin $(0.2 \mathrm{mg} / \mathrm{Kg}$ bodyweight $)$ oral administration on the progression of KCS in dogs was studied with two groups (A\&B)

\begin{tabular}{lll}
\hline Groups & $\begin{array}{l}\text { No. of } \\
\text { cases }\end{array}$ & Treatment \\
\hline A & 6 & Topical Gentamicin \& Tacrolimus $(0.1 \%)$ \\
B & 6 & $\begin{array}{l}\text { Topical Gentamicin \& Tacrolimus }(0.1 \%) \\
\end{array}$ \\
& & Tab Rosuvastatin $0.2 \mathrm{mg} / \mathrm{kg} /$ day for 2 weeks \\
\hline
\end{tabular}

Effect of Rosuvastatin on the progression of KCS was evaluated clinically \& photographically. mRNA expression of RhoA and GDI2 on ocular surface epithelial cells (OSEC) was identified by quantitative RT-PCR. Rho GTPase proteins RhoA, Rac1 and GDI2 was identified in tear film of treatment groups by western blotting before treatment and on days 14,21 and $28^{\text {th }}$ post- treatment.

\section{Ethics Statement}

Due permission to conduct the clinical study was obtained from Committee for the Purpose of Control And Supervision of Experiments on Animals, Ministry of environment, Forest and climate change, Government of India (No.F.25/17/2019-CPCSEA dated 25/09/2019).

\section{Collection of tear and ocular surface epithelial cells and mRNA isolation}

Tear samples were collected using Schirmer tear test (STT) ophthalmic strips (Optitech eyecare, Med devices life sciences limited, Ireland) in $0.5 \mathrm{ml}$ sterile eppendorf tubes and were frozen at $-60^{\circ} \mathrm{C}$ for MALDI-TOF and western blot experiments. Conjunctival / ocular surface epithelial cells were collected using Nitrocellulose membrane (Mixed Cellulose Ester Membrane, size of the pore: $0.22 \mu \mathrm{m}$, diameter GSWP: Merck Millipore Ltd. IRL) and a sterile swab. The conjunctival samples were 
preserved in a properly sterilized and $0.1 \%$ DEPC treated $2 \mathrm{ml}$ Eppendorf tubes with RNA later and stored at $-60^{\circ} \mathrm{C}$ deep freezer until processing (Sowbharenya et al., 2019). mRNA was isolated from the OSECs of KCS affected dogs using the conventional TRIzol method according to the manufacturer's protocol (Pilson et al., 2015). Purified RNA was reverse transcribed to cDNA using Verso cDNA Synthesis kit (Thermo Scientific, California), following the manufacturer's instructions.

\section{Tear sample processing}

Tear fluid was extracted from Schirmer's strips by placing STT strips in $0.5 \mathrm{ml}$ Eppendorf tube which was punctured at the bottom with a cannula. The tube was then transferred into a larger $(1.5 \mathrm{ml})$ Eppendorf tube and was centrifuged at $14,000 \mathrm{rpm}$ for 10 minutes at $4^{\circ} \mathrm{C}$ (Argueso et al., 2002). The centrifugal force pulled the tear fluid out of the Schirmer strip, through the central "pore" in the bottom of the smaller tube and into the outer $1.5 \mathrm{ml}$ tube (Posa et al., 2013). Tear samples were treated with protease inhibitor and stored at $-60^{\circ} \mathrm{C}$ until processing.

\section{Identification of molecular signature of Rho GTPases in tear through MALDI-TOF/MS and PMF}

After incubation with $10 \mu 150 \mathrm{nM}$ PBS elution buffer and protease inhibitor cocktail at $4^{\circ} \mathrm{C}$ for $20 \mathrm{~h}$, tear fluid was eluted from STT strips by centrifugation@15000 rpm/ min at $4^{\circ} \mathrm{C}$. Total protein concentration in the pooled tear sample was measured by BCA protein estimation kit (GeNei ${ }^{\mathrm{TM}}$, Bangalore) using bovine serum albumin as the standard. Pooled tear samples were diluted to final concentration of $30 \mu \mathrm{g} / 10 \mu \mathrm{l}$ with sterile distilled water and were run for molecular weight based differentiation of proteins using1D-SDS PAGE (Sambrook and Russell, 2006). Following separation of protein bands by $1 \mathrm{D}$ SDS-PAGE, the de-stained gel was transferred to a clean, sterile, and transparent plastic plate. At least three gel bands (in duplicate, $n=3$ ) corresponding to molecular weight of desired proteins were cut and processed for mass spectrometry. MALDI-MS measurements were performed (MALDI TOF/MS) and internally calibrated spectra were acquired on a Bruker Daltonics model Ultraflex II Spectrometer. Mass spectra generated were used for PMF with MS-FIT for Swissprot 2017-06 database with following parameters: global modification of carbamidomethyl $(\mathrm{C})$; possible modification as oxidation (M), Peptide mass tolerance of 300 ppm, Fragment mass tolerance of $0.1 \mathrm{Da}$ and 1 missed cleavage. Stringency was ensured by minimum matches of at least 4 peptides for individual protein detection through MS-FIT.

\section{Dynamics of Rho GTPases in Tear fluid after} Rosuvastatin treatment through immune-blotting

Equal volume of pooled tear fluids collected before and after Rosuvastatin treatment was run on $12 \%$ sodium dodecyl sulfate (SDS)-polyacrylamide gel. The resolved protein was then transferred onto a polyvinylidene difluoride (PVDF) membrane using a wet method blotting apparatus (GeNie) in $1 \mathrm{X}$ transfer buffer at $250 \mathrm{~mA}$ constant current for $2 \mathrm{hrs}$. The unbound surface of the membrane was blocked overnight with $5 \% \mathrm{BSA}$ at $4^{\circ} \mathrm{C}$. Following washing with TBS-Tween $(0.05 \%) 3$ times for ten min, the membranes were treated with primary antibodies for RhoA (1:1000), Rac1 (1:1000) and GDI2 (1:1000) and incubated for 3 hours in a shaker. It was washed again with TBS Tween $(0.05 \%) 3$ times for ten minutes. Finally, the membrane was treated with horse radish peroxidase conjugated goat anti-rabbit IgG (1:10,000; Chongqing Biospes Co., Ltd) and incubated at $37^{\circ} \mathrm{C}$ for $2 \mathrm{hrs}$. The membrane was washed 5 times with TBS-Tween and subsequently developed with DAB solution.

\section{In-Situ detection of Rho GTPase in Corneal tissue through Immuno-histochemistry (IHC)}

Immuno-histochemistry was performed with standard methods to localize the RhoA, Rac1 and GDI2 proteins in corneal tissue specimen with primary antibodies of said proteins as mentioned in previous section. Corneal tissue was collected fresh from cadaver of dogs died/euthanized due to conditions unrelated to this study and which have no ocular manifestation of KCS, after obtaining written consent from the owner. Corneal tissue from KCS affected dogs was collected while they have undergone surgical procedures for deep corneal ulcer such as keratoplasty.

\section{Design of primers for Real Time Polymerase Chain Reaction (qRT-PCR)}

The primers specific for dogs were designed using the software PrimerQuest, Integrated DNA Technologies 
[http://www.idtdna.com/SciTools/SciTools.aspx] with sequence data from the NCBI database (Table 2) and were chemically synthesized from Integrated DNA Technologies.

\section{Polymerase Chain Reaction (PCR)}

The PCR was performed using cDNA prepared from ocular surface epithelial cells. GAPDH was selected as reference gene for normalization of the genes of interest. The annealing temperature for the individual primer sets were optimized using gradient PCR. For optimization of annealing temperature, reaction mixture was divided in 4 tubes of $25 \mu \mathrm{l}$ each, which were subjected to different annealing temperatures in a gradient PCR machine. The reaction components were subjected to cyclic conditions mentioned in table 3 .

Annealing temperatures ranging between $54-62^{\circ} \mathrm{C}$ were set in different blocks of gradient PCR machine for optimization. The PCR products formed at different annealing temperatures were analyzed along with DNA ladder by agarose gel electrophoresis (AGE) for specified amplicons of expected size. For AGE appropriate quantity of agarose was weighed and dissolved in $0.5 \mathrm{X}$ TBE buffer by boiling and was allowed to cool to $45^{\circ} \mathrm{C}-50^{\circ} \mathrm{C}$ and then $0.5 \mu \mathrm{g} / \mathrm{ml}$ ethidium bromide was added. This mixture was poured in gel casting tray with comb and left for setting.
When the gel was solidified, comb was carefully removed. Tray with gel was submerged in an electrophoresis tank containing $0.5 \mathrm{X}$ TBE buffer. $10 \mu \mathrm{l}$ of PCR product to be analysed was mixed with $2 \mu \mathrm{l}$ of $6 \mathrm{X}$ loading dye and loaded into separate wells of agarose gel along with $5 \mu \mathrm{l}$ of standard molecular weight marker 50bp DNA ladder. Electrophoresis was performed at $100 \mathrm{~V}$ for $45 \mathrm{~min}$ and the mobility monitored by the movement of the dye. After sufficient migration, the bands of expected size were observed under UV light and photographed using the gel documentation system. Annealing temperatures at which best yield of specific amplicon was observed, were selected as optimum annealing temperatures for the individual primer sets.

\section{mRNA quantification of Rho GTPases in OSCE cells post Rosuvastatin treatment through qRT-PCR}

Real time PCR (qRT-PCR) was used to enumerate the relative mRNA expression level of RhoA, GDI2 and GAPDH genes. Quantitative real time PCR (qRT-PCR) was performed in the CFX96 connectTM Real time PCR system (Bio Rad, USA). qRT-PCR reaction components and cyclic conditions for amplification of RhoA, Rac1, GDI2 and GAPDH are mentioned in table 4 and 5, respectively. cDNA was amplified on the same plate for all the three primer pairs to ensure equal amplification conditions. Specificity of amplification products was

Table 2: Primer pair and amplification conditions of gene of interest

\begin{tabular}{|c|c|c|c|c|}
\hline Gene & Sequence of the primer & $\operatorname{Tm}\left({ }^{\circ} \mathrm{C}\right)$ & Product length(bp) & Reference \\
\hline \multirow[t]{2}{*}{ RhoA } & F- 5' GTGGCAGATATTGAAGTTGATGG 3' & 49.4 & 105 & Self designed \\
\hline & R-5’ AGTGTCTGGATAGGAGAGAGG 3' & & & \\
\hline \multirow[t]{2}{*}{$\mathrm{GDI}_{2}$} & F-5' GGCACCTACATGCTCAATAAAC 3' & 49.65 & 89 & Self designed \\
\hline & R-5’ CGAGCAACCTCTCCTTCAG 3' & & & \\
\hline \multirow[t]{2}{*}{ GAPDH } & F-5' TGACACCCACTCTTCCACCTTC 3' & 58.8 & 105 & Nam et al., 2015 \\
\hline & R-5' CGGTTGCTGTAGCCAAATTCA 3' & & & \\
\hline
\end{tabular}

Table 3: PCR cycling conditions for the amplification of the genes of interest

\begin{tabular}{lllll}
\hline SI. No. & Steps & Temperature $\left({ }^{\circ} \mathbf{C}\right)$ & Time & No. of cycles \\
\hline 1 & Initial Denaturation & 94 & $5 \mathrm{~min}$ & 1 \\
2 & Denaturation & 94 & $1 \mathrm{~min}$ & \\
& Annealing & $54-62$ & $1 \mathrm{~min}$ & 36 \\
& Extension & 72 & $1 \mathrm{~min}$ & 1 \\
\hline
\end{tabular}


confirmed by melting curve and analysis. For each sample, results were documented as cycle threshold (CT) values. GAPDH was used for normalization of the data for variation in the amount of input RNA. The relative fold change values were calculated based on the average normalized $\mathrm{CT}$ values $(\Delta \mathrm{CT})$. The relative expression of each sample was calculated using the $2 " \Delta \Delta \mathrm{CT}$ method with control group as calibrator and the $\log 2$ fold change was plotted.

Table 4: qRT-PCR reaction components for the amplification of RhoA, Rac1, GDI ${ }_{2}$ and GAPDH

\begin{tabular}{ll}
\hline Reaction component & Quantity \\
\hline SYBR Premix Ex Taq (2x) & $10 \mu \mathrm{L}$ \\
Forward primer (5 pmole) & $0.5 \mu \mathrm{L}$ \\
Reverse primer (5 pmole) & $0.5 \mu \mathrm{L}$ \\
cDNA (sample) & $1 \mu \mathrm{L}$ \\
Nuclease free water & $8 \mu \mathrm{L}$ \\
\hline
\end{tabular}

Table 5: qRT-PCR cycling conditions for the amplification of the genes of interest

\begin{tabular}{llll}
\hline Step & Temperature $^{\circ} \mathbf{C}$ & Duration & Cycles \\
\hline Initial denaturation & 95 & $30 \mathrm{sec}$ & 1 \\
Denaturation & 95 & $5 \mathrm{sec}$ & 40 cycles \\
Annealing & 60 & $30 \mathrm{sec}$ & \\
Melt curve & 65 & $30 \mathrm{sec}$ & \\
\hline
\end{tabular}

\section{Statistical analysis}

Data were analyzed using Statistical Program for Social Sciences (SPSS 20 IBM). Two-way ANOVA test was used to compare the parametric data at different time intervals between the groups. The non-parametric data generated from the scoring were analyzed using Mann-Whitney $\mathrm{U}$ test to check for significance between the groups at corresponding time intervals. Wilcoxon Signed Ranks Test was used for non-parametric data to check significance between intervals. A value of $\mathrm{P}<0.05$ was considered to be statistically significant. All the graphs were prepared in Graph Pad Prism (Version 5).

\section{RESULTS AND DISCUSSION}

Mechanobiological clues underlying the pathology of $\mathrm{KCS}$ in dogs are not laid down yet. Immune cell targeting of lacrimal gland and lacrimal acinar destruction is one of the purported pathology behind KCS. Moreover, integrity of corneal surface and its light reflecting power is progressively attenuated in KCS progression as evidenced by waning corneal clarity, corneal opacity, neovascularisation and corneal pigmentation. Rho GTPases has a role in immune cell migration towards lacrimal gland and fibroblastic transformation of corneal keratocytes residing in corneal stroma which is also modulated by the structure and stiffness of ECM ie, corneal stroma. Role of Rho GTPases in early and late stages of $\mathrm{KCS}$ in dogs is explored through tear film proteomics and western blotting. Effect of Rho GTPase modulation by Rosuvastatin was explored through mRNA expression of Rho GTPases in OCSE and also through tear film western blotting.

In present study, all dogs diagnosed with KCS as primary ocular pathology belonged to Chinese Pug breed. Pugs of age group of 1-5 years were affected with $\mathrm{KCS}$ in more number (54\%) followed by 6-11 years old dogs (37\%) and $\leq 1$ year old dogs $(9 \%)$. Similar age distribution of KCS cases was observed by John et al. (2018). Males were affected more (57\%) compared to females (43\%) in the present study. Similar observations were recorded by Hartley et al. (2006) whereas, KCS was observed more in female by John et al. (2018) and Sansom and Barnett (1985). Chinese Pugs were found prone to KCS due to head conformation causing exophthalmos. Among brachycephalic breeds, Pug is one which has an extreme brachycephalic head shape (Maggs et al., 2008) and they might show various conformational abnormalities of the eye including exophthalmos, macro palpebral fissure and lagophthalmos (Bedford and Jones, 2001). Increased tear evaporation and very less corneal sensitivity also predispose this breed to KCS (Renwick, 1996). Early KCS cases were having better blink reflex, less corneal pigmentation and significantly more tear production compared to late KCS cases. Similar finding has been reported by John et al. (2018). Since the corneal pigmentation causes some hindrance to vision, the increased area of corneal pigmentation and corneal opacity in late KCS might be the reason for their sluggish blink reflex.

Total protein concentration in tear samples of early KCS $(\mathrm{Mean} \pm \mathrm{SE}$ value of $18.10 \pm 7.652 \mu \mathrm{g} / \mu \mathrm{l})$ and late $\mathrm{KCS}$ (Mean \pm SE value of $18.92 \pm 4.916 \mu \mathrm{g} / \mu \mathrm{l}$ ) were higher compared to that in normal tear $(\mathrm{Mean} \pm \mathrm{SE}$ value of 
$4.840 \pm 1.787 \mu \mathrm{g} / \mu \mathrm{l})$. Significant increase in tear protein in KCS cases has been reported by Disney (2017). Increased level of inflammatory mediators and decreased amount of tear production could be a reason behind this. $\mathrm{Wu}$ and Zhang (2007) reported that the different level of proteins between diseased and normal tear sample might be due to high or low expression of proteins; abnormally shed proteins; modified proteins; cleaved proteins of proteolysis or proteosome activity. Tear protein resolution by SDS-PAGE had been used as a tool for the detection dynamics of tear proteins in dry eye of man (Grus et al., 2002). MALDI-TOF mass spectra could be used to identify disease state markers, and may find application in the diagnosis of the dry eye condition (Ham et al., 2007). Prominent proteins bands in1D- SDS PAGE of normal, early and late KCS tear proteins were analysed through MALDI-TOF/ MS and proteins were identified through peptide mass fingerprinting (PMF) with MS-FIT analysis against protein database SwissProt. 2017.11.01. There was a significant down-regulation of Rho GTPaseactivating protein 7 (DLC1) in early and late stage of
KCS compared to normal tear $(\mathrm{p}<0.001)$. Transforming protein RhoA, Ras-related C3 botulinum toxin substrate 1 and Rho modulator Rab GDP dissociation inhibitor beta, Rho guanine nucleotide exchange factor 2 were found up-regulated in early stage of KCS along with many Rasrelated Rab-proteins (Fig. 1). DLC1 is a tumour suppressor and negatively regulator of RhoA, B and C. Transdifferentiation of native keratocytes and its organisation of actomyosin network are regulated by Rho GTPases (Hall and Nobes, 2000). Rho signalling regulates the assembly of actomyosin filaments and focal adhesions, influences gene expression, cell proliferation, endocytic and exocytic pathways, and cellular transformation (Schmandke et al., 2007) and activation of RhoA was found necessary for TGF- $\beta$ mediated expression of $\alpha$-SMA in keratocytes; a marker of smooth muscle transformation of keratocytes (Harvey et al., 2007). Proteomic data through MALDITOF/MS revealed increased Rho GTPase-activating protein 7 (DLC1) signature in normal tear which might have a protective role in modulating Rho GTPase expression and its significant down regulation and altered

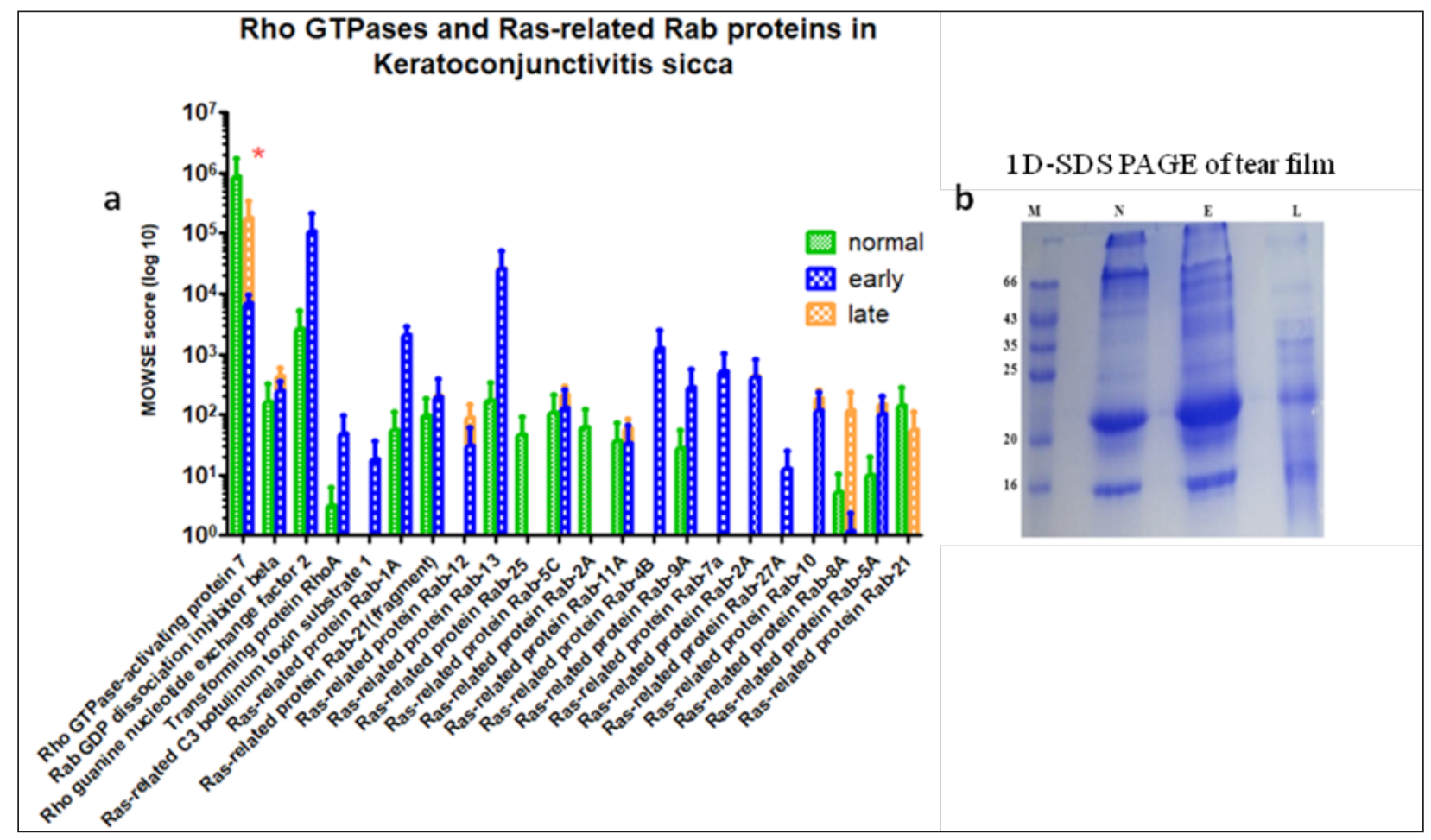

Fig. 1: (a) Dynamics of Rho GTPase-activating protein in normal, early and late KCS cases; (b) Coomassie blue-stained SDS-PAGE showing canine tear proteins profile of normal, early KCS and late KCS Lane M : Popular range protein ladder Lane; N : Pooled tear sample of normal animal Lane; E : Pooled tear sample of early KCS Lane; L : Pooled tear sample of late KCS 
cellular signalling behind the pathology of KCS. This result was confirmed by tear western blotting with Rho GTPases. This also gives a proof to our concept that Rho GTPase modulation by statins can have ameliorative effect in the progression of KCS. Protein expression of RhoA, Rac1 and GDI2 in the tear fluid from normal, early and late KCS cases was assessed by western blotting (Fig. 2a, $\mathrm{b}$ and $\mathrm{c}$ ). RhoA and Racl proteins showed more intense bands in early KCS and late KCS compared to normal tear. Rho GTPase activity was increased in inflammatory conditions and immune mediated diseases which explains its increased expression in early and late KCS (Hall, 2012). Variability in the expression of Rho-GDI2 proteins in KCS was much low compared to normal as was found in human breast tumours (Fritz et al., 2002).

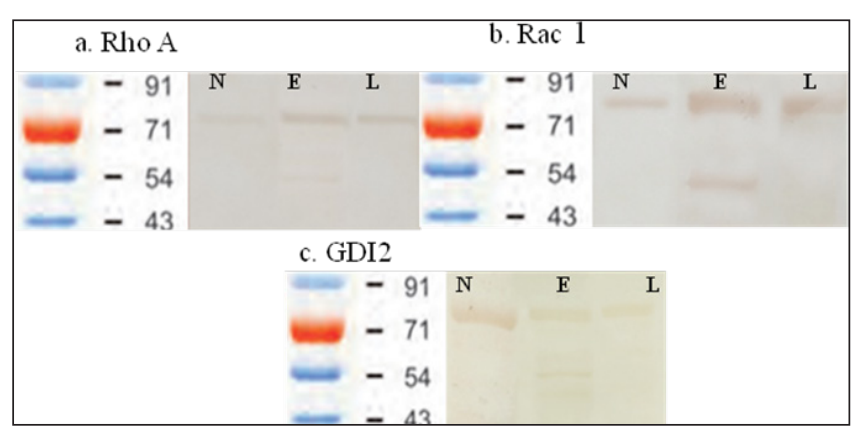

Fig. 2: The expression of Rho A, Rac 1 and GDI2 proteins in the tear fluid of normal $(\mathrm{N})$, early KCS (E) and late KCS (L) animals by western blotting

Rho GTPases, in our blotting study, was found to be in oligomerized state rather than in their low molecular weight native form since protein bands were observed at $\sim 60-70$ $\mathrm{kDa}$. RhoA, Cdc42 can exist in dimeric form whereas Raclexists in reversible monomeric and ologomeric states (Zhang et al., 2001). Homo oligomerized cellular Rac1 was found to have significantly higher intrinsic GTPase activity compared to its monomer and hence it had a regulatory role of basal GTPase activity (Zhang et al., 2001). Rho GTPases Cdc42, RhoA, and Rac2 are capable of forming homodimers, and the dimerization may play a role in the negative regulation of the GTPases (Zhang et al., 1999). Phosphorylation and ribosylation of Rho GTPases are also possible PTM modifications (Rohrbeck et al., 2016).

Results of immuno-histochemistry analysis showed sparse expression of RhoA in normal ocular tissue, mild expression in corneal connective tissue stroma of early KCS cornea and abundant expression in corneal epithelial cells in late KCS cornea. Mild expression of Rac 1 was noticed in corneal connective tissue stroma of normal and early KCS eyes whereas moderate to abundant expression was noticed in the corneal epithelial cells of late KCS (Fig. 3 ). Mild to moderate expression of GDI2 was noticed in corneal connective tissue stroma of normal and early KCS eyes whereas moderate to high expression was noticed in the corneal epithelial cells of late KCS. IHC results are corroborated with the results of western blotting. Presence of Rho GTPases in the normal ocular tissues like cornea, lens and retina of mouse was identified by Mitchell et al. (2007). Experimentally, RhoA expression was detected in the endothelial cells and the surface layer of epithelial cells of the corneal epithelium with little detectable staining in the columnar cells in the cornea of the adult mouse eye. In the corneal stroma, a strong staining was detected in the bodies of some fibroblasts. Rac1 was predominantly expressed in the entire layers of corneal epithelium (both columnar and squamous cell layers) but absent in both corneal stroma and the endothelial cells layer (Mitchell et al., 2007). Increased Rho GTPase staining in early and late KCS might be suggestive of enhanced fibroblastic activity in corneal stroma during development of KCS in dogs.

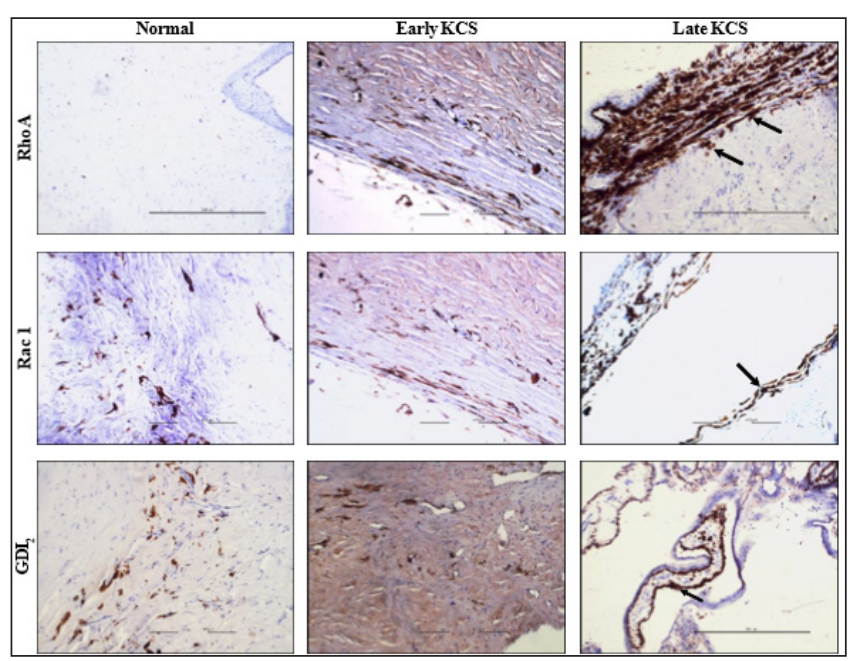

Fig. 3: Expression of Rho A, Rac 1 and GDI2 in ocular tissue of normal, early KCS and late KCS cases by immunohistochemistry

Blink reflex increased in group A post treatment on days 7, 21 and 28 whereas no such improvement was notice 
in group B. Ocular discharge decreased significantly $(\mathrm{P}<0.05)$ on post treatment day 28 in both groups (Table 6). Conjunctival hyperaemia decreased significantly post treatment in group A $(p<0.05)$ and group B $(0.01)$. There was gradual but non-significant increase in the STT values after treatment at different post-treatment intervals in both groups. A significant $(\mathrm{P}<0.05)$ increase in corneal clarity was noticed in group B on post treatment days 21 and 28 compared to pre-treatment compared to group A (Table 6). Pleotropic effect of Rosuvastatin includes antiinflammatory and vascular attenuation which could play a role in reducing the burden of a variety of ophthalmic pathologies as in dry eye, glaucoma, macular degeneration, diabetic retinopathy etc. (Ooi et al., 2019). Ooi et al. (2015) suggested that $\mathrm{HMG}$ CoA reductase inhibitor; preferably a statin could be used for the treatment of dry eye.

Area of corneal pigmentation increased in group A post treatment whereas a decrease in area of pigmentation was noticed in Group B though these changes were not statistically significant. Similarly corneal pigmentation density was also found to decrease in group B post treatment compared to group A (Table 6). In group A, there was significant $(\mathrm{P}<0.05)$ decrease in conjunctival hyperemia on post treatment day 21 (Table 6 and Fig. 4). Whereas, in group $\mathrm{B}$ significant $(\mathrm{P}<0.01)$ decrease in conjunctival hyperemia was noticed on post treatment day 21 and 28 .
Better response in terms of conjunctival hyperemia in group B animals can be attributed to the anti-inflammatory effect of Rosuvastatin. Better response in terms of corneal pigmentation was observed in group B animals compared to group A. High-dose statins may result in resolution of drusenoid pigment epithelial detachments (PEDs) and improvement in visual acuity (Vavvas et al., 2016).

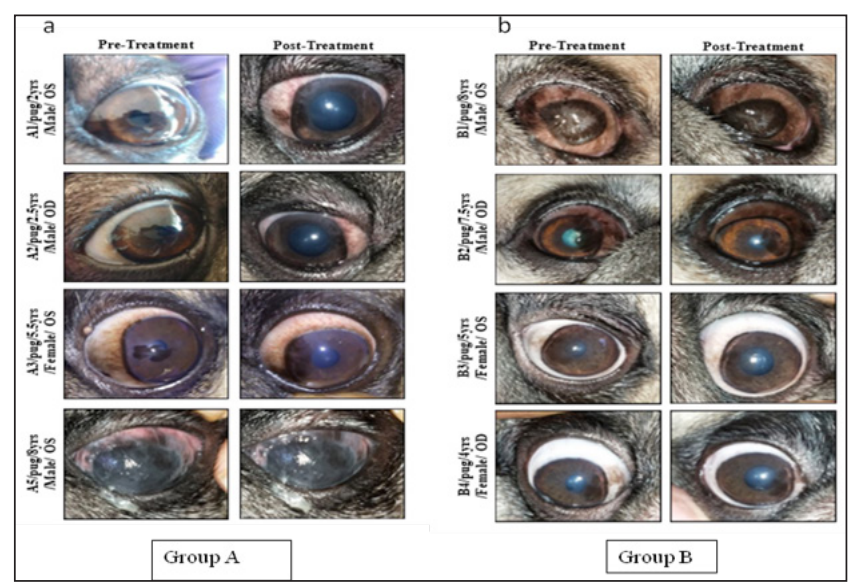

Fig. 4: Corneal pigmentation before and after treatment in both the groups

Western blotting analysis showed increased protein expression of Rho GTPases in group B tear film after treatment which can be due to inhibitory effect of

Table 6: Median (min-max) with Mean rank of blink reflex, ocular discharge, conjunctival hyperemia, corneal clarity, corneal vessel length, corneal pigmentation area scores in the animals of groups A and B on different days on a score scale of 1-4

\begin{tabular}{|c|c|c|c|c|c|c|c|c|c|}
\hline \multirow[b]{2}{*}{ Groups } & \multirow[b]{2}{*}{ Parameters } & \multicolumn{2}{|l|}{ Pre-treatment } & \multicolumn{2}{|c|}{ Day 7 Post -treatment } & \multicolumn{2}{|c|}{ Day 21 Post -treatment } & \multicolumn{2}{|c|}{ Day 28 Post -treatment } \\
\hline & & $\begin{array}{l}\text { Median (Min- } \\
\text { Max) }\end{array}$ & $\begin{array}{l}\text { Mean } \\
\text { Rank }\end{array}$ & $\begin{array}{l}\text { Median } \\
\text { (Min-Max) }\end{array}$ & $\begin{array}{l}\text { Mean } \\
\text { Rank }\end{array}$ & $\begin{array}{l}\text { Median (Min- } \\
\text { Max) }\end{array}$ & $\begin{array}{l}\text { Mean } \\
\text { Rank }\end{array}$ & $\begin{array}{l}\text { Median (Min- } \\
\text { Max) }\end{array}$ & $\begin{array}{l}\text { Mean } \\
\text { Rank }\end{array}$ \\
\hline A & Blink reflex & $2.00(1-3)$ & 5.17 & $2.50(2-3)$ & 5.75 & $3.00(2-3)$ & 6.17 & $3.00(2-3)$ & 6.17 \\
\hline B & & $3.00(1-3)$ & 7.83 & $3.00(1-3)$ & 7.25 & $3.00(1-3)$ & 6.83 & $3.00(1-3)$ & 6.83 \\
\hline A & Ocular discharge & $2.00(2-3)$ & $6.50^{\mathrm{a}}$ & $2.00(2-3)$ & $7.00^{\mathrm{a}}$ & $2.00(1-2)$ & 7.5 & $1.00(1-2)$ & $7.50^{\mathrm{b}}$ \\
\hline B & & $2.00(2-3)$ & $6.50^{\mathrm{a}}$ & $2.00(2-3)$ & $6.00^{\mathrm{a}}$ & $1.00(1-2)$ & 5.5 & $1.00(1-1)$ & $5.50^{\mathrm{b}}$ \\
\hline A & Conjunctival & $2.50(2-4)$ & $6.50^{\mathrm{a}}$ & $2.00(2-3)$ & 7.83 & $1.50(1-2)$ & $8.00^{\mathrm{b}}$ & $2.00(1-2)$ & 8.5 \\
\hline B & hyperemia & $2.50(2-4)$ & $6.50^{\mathrm{a}}$ & $2.00(1-2)$ & 5.17 & $1.00(1-1)$ & $5.00^{\mathrm{b}}$ & $1.00(1-1)$ & $4.50^{\mathrm{b}}$ \\
\hline A & Corneal clarity & $2.50(1-4)$ & 6.5 & $2.50(1-3)$ & 6 & $2.50(1-3)$ & 6.92 & $2.50(1-3)$ & 6.92 \\
\hline B & & $2.50(2-4)$ & $6.5^{\mathrm{a}}$ & $2.50(2-4)$ & $7.00^{\mathrm{a}}$ & $2.00(1-4)$ & $6.08^{\mathrm{b}}$ & $2.00(1-4)$ & $6.08^{b}$ \\
\hline A & Corneal vessel & $1.50(1-2)$ & 6.75 & $1.50(1-2)$ & 7.25 & $1.00(1-2)$ & 6.83 & $1.00(1-2)$ & 6.83 \\
\hline B & length & $1.00(1-4)$ & 6.25 & $1.00(1-4)$ & 5.75 & $1.00(1-4)$ & 6.17 & $1.00(1-4)$ & 6.17 \\
\hline A & $\begin{array}{l}\text { Corneal } \\
\text { pigmentation area }\end{array}$ & $3.00(1-5)$ & 6.67 & $3.00(1-5)$ & 6.67 & $3.50(1-5)$ & 7.25 & $3.50(1-5)$ & 7.842 \\
\hline $\mathrm{B}$ & & $2.50(2-5)$ & 6.33 & $2.50(2-5)$ & 6.33 & $2.00(2-5)$ & 5.75 & $2.00(2-5)$ & 5.58 \\
\hline
\end{tabular}


Rosuvastatin on Rho prenylation (Fig. 5). Statins might cause accumulation of unprenylated Rho-GTPase (Von Zee et al., 2009) in tissues after treatment.

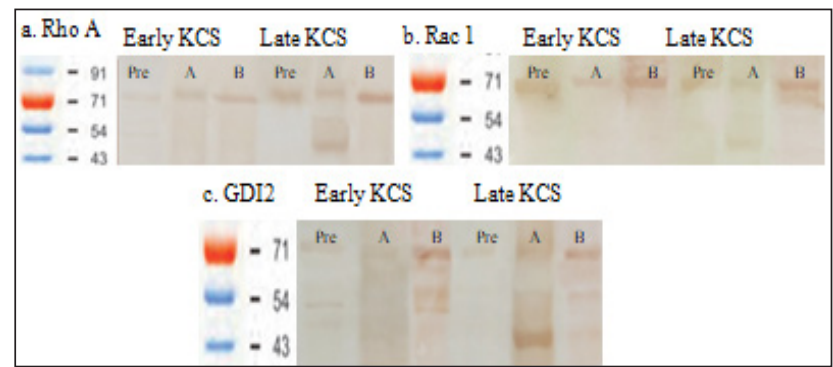

Fig. 5: The expression of RhoA (1), Rac1 (2) and GDI2 (3) proteins in the tear fluid of groups A and B animals before and after treatment by western blotting

The qRT-PCR melt curve analysis of the genes of interest (RhoA and GDI2) and the reference gene (GAPDH) revealed single sharp peaks at $\mathrm{Tm}$ ranging from 75 to $86^{\circ} \mathrm{C}$ (Fig. 6). Gene expression of both RhoA and GDI2 increased post treatment in both groups but increase in expression was contained to pre-treatment levels in group B compared to Group A (Fig. 6).

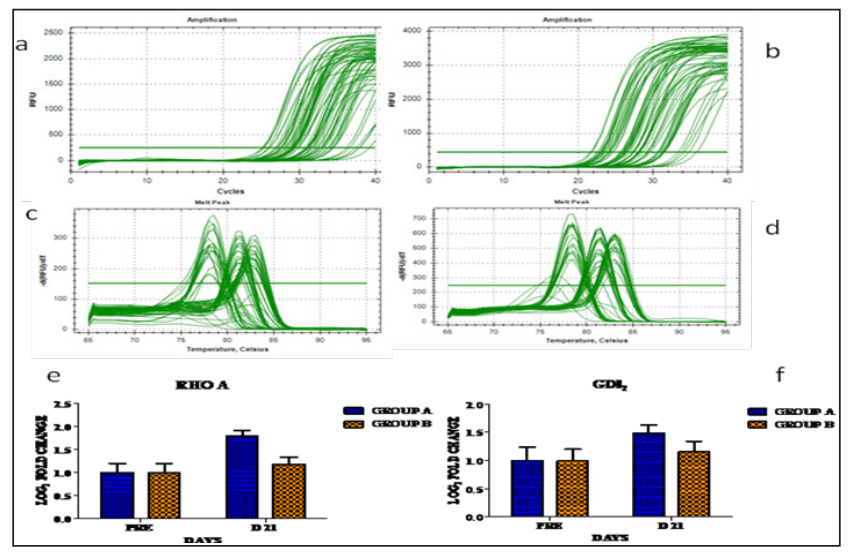

Fig. 6: Level of RhoA and GDI2 in the conjunctival impression cytology in group A and group B animals before and after treatment on day 7,21 and 28 by quantitative real time PCR ( $\log 2$ fold change is plotted with standard error of difference)

In our study, rosuvastatin was given for two weeks only. Future study with longer treatment period might give a clear picture of rho GTPase regulation be rosuvastatin. Contradictory to our result, Gbelcová et al. (2017) found that statin treatment resulted in upregulation of Rho A gene. There are conflicting reports in the literature, whether statins increase or decrease Rho GTP levels in intact cells (Turner et al., 2008). However, our study implies a clear advantage of rosuvastatin treatment in containing KCS progression in dogs.

\section{CONCLUSION}

Our study explored the dynamics of Rho GTPase proteins in the progression of KCS in dogs and therapeutic effect of a Rho modulator Rosuvastatin in blocking the disease progression. Rho GTPase-activating protein7 (DLC1) was found significantly down regulated in early and late stages of KCS and Rosuvastatin treatment could contain mRNA expression of RhoA and GDI2 and could arrest progression of KCS in dogs.

\section{ACKNOWLEDGEMENTS}

Authors gratefully acknowledge funds provided by DBT and ICAR-IVRI to conduct present research work.

\section{REFERENCES}

Argüeso, P., Balaram, M., Spurr-Michaud, S., Keutmann, H.T., Dana, M.R. and Gipson, I.K. 2002. Decreased levels of the goblet cell mucin MUC5AC in tears of patients with Sjogren syndrome. Invest. Ophthalmol. Vis. Sci., 43(4): 1004-1011.

Bedford, P. and Jones, G. 2001. Abnormal appearance. Small Animal Ophthalmology: A Problem-oriented Approach. $3^{\text {rd }}$ edition. W. B. Saunders, London, pp. 88.

Chen, J., Guerriero, E., Sado, Y. and SundarRaj, N. 2009. Rho-Mediated Regulation of TGF-1 and FGF-2-Induced Activation of Corneal Stromal Keratocytes. Invest. Ophthalmol. Vis. Sci., 50(8): 3662-3670.

Disney, J.L. 2017. Tear lacritin concentrations in canine keratoconjunctivitis sicca. Doctoral dissertation, Virginia Tech. pp. 20-31.

Dodi, P.L. 2015. Immune-mediated keratoconjunctivitis sicca in dogs: current perspectives on management. Vet. Med. (Auckl)., 6: 341-347.

Fritz, G., Brachetti, C., Bahlmann, F., Schmidt, M. and Kaina, B. 2002. Rho GTPases in human breast tumours: expression and mutation analyses and correlation with clinical parameters. Br. J. Cancer, 87(6): 635.

Gbelcová, H., Rimpelová, S., Ruml, T., Fenclová, M., Kosek, V., Hajšlová, J., Strnad, H., Kolář, M. and Vítek, L. 2017. Variability in statin-induced changes in gene expression profiles of pancreatic cancer. Sci. Rep., 7: 44219. 
Grus, F.H., Sabuncuo, P., Dick, H.B., Augustin, A.J. and Pfeiffer, N. 2002. Changes in the tear proteins of diabetic patients. BMC Ophthalmol., 2(1): 4.

Hall, A. 2012. Rho family gtpases. Biochem. Soc. Trans., 40(6): 1378-1382.

Hall, A. and Nobes, C.D. 2000. Rho GTPases: molecular switches that control the organization and dynamics of the actin cytoskeleton. Philos. Trans. R. Soc. Lond. B. Biol. Sci., 355: 965-970.

Ham, B.M., Jacob, J.T. and Cole, R.B. 2007. Single eye analysis and contralateral eye comparison of tear proteins in normal and dry eye model rabbits by MALDI-ToF mass spectrometry using wax-coated target plates. Anal. Bioanal. Chem., 387(3): 889-900.

Hartley, C., Williams, D.L. and Adams, V.J. 2006. Effect of age, gender, weight, and time of day on tear production in normal dogs. Vet. Ophthalmol., 9(1): 53-57.

Harvey, K.A., Paranavitana, C.N., Zaloga, G.P. and Siddiqui, R.A. 2007. Diverse signaling pathways regulate fibroblast differentiation and transformation through Rho kinase activation. J. Cell Physiol., 211: 353-363.

John, C., Gopinathan, A., Singh, K., Sharma, P., Sowbharenya, C. and Sarangom, S.B. 2018. Clinical evaluation of topical tacrolimus ointment usage in different stages of keratoconjunctivitis sicca in dogs. Turk. J. Vet. Anim. Sci., 42(4): 259-268.

Maggs, D.J. 2008. Cornea and sclera 10. Slatter's fundamentals of veterinary ophthalmology, Saunders Elsevier, UK, pp. 175.

McFarland, A., Anoopkumar-Dukie, S., Arora, D., Grant, G., McDermott, C., Perkins, A. and Davey, A. 2014. Molecular mechanisms underlying the effects of statins in the central nervous system. Int. J. Mol. Sci., 15(11): 20607-20637.

Mitchell, D.C., Bryan, B.A., Liu, J.P., Liu, W.B., Zhang, L., Qu, J., Zhou, X., Liu, M. and Li, D.W. 2007. Developmental expression of three small GTPases in the mouse eye. Mol. Vis., 13: 1144

Ooi, K.G., Khoo, P., Vaclavik, V. and Watson, S.L., 2019. Statins in ophthalmology. Surv. Ophthalmol., 64(3): 401-432.

Ooi, K.G.J., Wakefield, D., Billson, F.A. and Watson, S.L. 2015. Efficacy and safety of topical atorvastatin for the treatment of dry eye associated with blepharitis: a pilot study. Ophthalmic Res., 54(1): 26-33.

Pilson, Q., Jefferies, C.A., Gabhann, J.N. and Murphy, C.C. 2015. Isolation of microRNA from conjunctival impression cytology. Exp. Eye Res., 132: 109-114.

Posa, A., Bräuer, L., Schicht, M., Garreis, F., Beileke, S. and Paulsen, F. 2013. Schirmer strip vs. capillary tube method: non-invasive methods of obtaining proteins from tear fluid. Ann. Anat., 195(2): 137-142.
Renwick, P. 1996. Diagnosis and treatment of corneal disorders in dogs. In Pract., 18(7): 315-328.

Rohrbeck, A., Fühner, V., Schröder, A., Hagemann, S., Vu, X.K., Berndt, S., Hust, M., Pich, A. and Just, I. 2016. Detection and quantification of ADP-ribosylated RhoA/B by monoclonal antibody. Toxins., 8(4): 100.

Sambrook, J. and Russell, D.W. 2006. SDS-polyacrylamide gel electrophoresis of proteins. CSH Protoc., 2006(4): 540.

Sansom, J. and Barnett, K.C. 1985. Keratoconjunctivitis sicca in the dog: a review of two hundred cases. J. Small Anim. Pract., 26(3): 121-131.

Saoudi, A., Kassem, S., Dejean, A.S. and Gaud, G. 2014. RhoGTPases as key regulators of T lymphocyte biology. Small GTPases, doi.org/10.4161/sgtp.28208

Schmandke, A., Schmandke, A. and Strittmatter, S.M. 2007. ROCK and Rho biochemistry and neuronal functions of Rhoassociated protein kinases. Neuroscientist.,13: 454-469.

Sowbharenya, C., Singh, K., Gopinathan, A. and Agrawal, R. K. 2019. Evaluation of three different impression cytology techniques for RNA retrieval from canine ocular surface epithelial cells. Res. J. Biotechnol., 14 (10) E Journal (E-ISSN 2278-4535; PRINT-ISSN 0973-6263)

Toksoz, D., Merdek, K.D. 2002. The Rho small GTPase: functions in health and disease. Histol Histopathol., 17: 915927.

Turner, S.J., Zhuang, S., Zhang, T., Boss, G.R. and Pilz, R.B. 2008. Effects of lovastatin on Rho isoform expression, activity, and association with guanine nucleotide dissociation inhibitors. Biochem. Pharmacol., 75(2): 405-413.

Vavvas, D.G., Daniels, A.B., Kapsala, Z.G., Goldfarb, J.W., Ganotakis, E., Loewenstein, J.I., Young, L.H., Gragoudas, E.S., Eliott, D., Kim, I.K. and Tsilimbaris, M.K. 2016. Regression of some high-risk features of age-related macular degeneration (AMD) in patients receiving intensive statin treatment. EBioMedicine., 5: 198-203.

Von Zee, C.L., Richards, M.P., Bu, P., Perlman, J.I. and Stubbs, E.B. 2009. Increased RhoA and RhoB protein accumulation in cultured human trabecular meshwork cells by lovastatin. Invest. Ophthalmol. Vis. Sci., 50(6): 2816-2823.

$\mathrm{Wu}, \mathrm{K}$. and Zang, Y. 2007. Clinical application of tear proteomics: Present and future prospects. Proteo. Clin. Appl., 1: 972-982.

Zhang, B., Gao, Y., Moon, S. Y., Zhang, Y. and Zheng, Y. 2001. Oligomerization of Racl GTPase Mediated by the Carboxylterminal Polybasic Domain. J. Biol. Chem., 276(12): 89588967

Zhang, B., Zhang, Y., Collins, C.C., Johnson, D., Zheng, Y. 1999. A Built-in Arginine Finger Triggers the Self-stimulatory GTPase-activating Activity of Rho Family GTPases. $J$. Biol. Chem., 274: 2609-2612. 